\title{
MONITORING PEWAKTUAN PENGISIAN AIR DARI SUMBER SAMPAI KE TANGKI DENGAN MENGGUNAKAN PLC OMRON
}

\author{
Toto Raharjo, Ismail \\ Prodi Teknik Elektro UNPAM \\ Jln Puspiptek Raya No 11 Buaran, Tangerang Selatan 15310 INDONESIA \\ e-mail : ismail090992@gmail.com
}

\begin{abstract}
ABSTRAK
Telah dibuat monitoring pewaktuan pengisian air dari sumber sampai ketangki dengan menggunakan PLC omron. Alat tersebut untuk membantu memonitoring pengisian dari sumber kesebuah storagetank. Penelitian ini bertujuan membuat seperangkat sistem monitoring pewaktuan pengisian air dari sumber sampai ketangki dengan menggunakan PLC omron dan mengetahui cara kerja sistem monitoring pewaktuan pengisian air dari sumber sampai ketangki dengan menggunakan PLC omron.Pembuatan alat monitoring menggunakan sensor level air (float switch) sebagai pendeteksi air pada sebuah storage tank kemudian memberi perintah ke PLC dengan menggunakan software CX-Programmer.Hasil percobaan menunjukkan pengisian air pada sebuah storage tank menggunakan level sensor float switch yang berfungsi sebagai start dan stop pompa pengisian air.Alat monitoring menggunakan PL Comron CP1E untuk menginformasikan pengisian waktu normal di bawah 200 detik dengan menyalanya lampu indicator hijau,menginformasikan pengisian warning saat waktu pengisian melebihi 200 sampai dengan270 detik dengan menyalanya lampuin dikator kuning,dan akan menginformasikan pengisian trouble saat waktu pengisian melebihi 270 detik sampai waktu tak terhingga dengan menyalanya lampu indicator merah bersamaan dengan bunyi buzzer untuk setiap pengisian tangka bervolume 21 liter.Program monitoring waktu pengisian air ketangki menggunakan software CX-Programmer, dimana waktu pengisian normal di bawah 200 detik, waktu pengisian warning melebihi 200 sampai dengan 270 detik dan waktu pengisian trouble melebihi 270 detik.

Kata kunci :CX-Programmer, PLC CP1E, Float Switch Censor
\end{abstract}

\begin{abstract}
Has made monitoring the timing of charging the water from the source to the tank using omron PLC.Such a tool to help monitor the charging of sources into a storage tank. This research aims to create a set of monitoring system timing replenishing water from the source to the tank using omron PLC and know how the system of monitoring the timing of charging the water from the source to the tank using omron PLC. Making monitoring tool using the water level sensor (float switch) as detection of water in a storage tank and then give the command to the PLC using CX-Programmer software. The experimental results showed replenishing water in a storage tank using level sensors float switch that serves as the start and stop the charging pump water. Monitoring tool using PLC omron CP1E to inform the charging time is normally less than 200 seconds with menyalanya green indicator lights, informing the charging warning when the charging time exceeds 200 up to 270 seconds with menyalanya yellow indicator light, and will inform the charging trouble when the charging time exceeds 270 seconds until infinity with flaring red indicator light simultaneously with buzzer sound for each filling the tank volume 21 liters. Charging time water monitoring program to the tank using the CXProgrammer software, where the normal charging time of less than 200 seconds, the charging time warning exceeded 200 to 270 seconds and trouble charging time exceeds 270 seconds.
\end{abstract}

Keywords: CX-Programmer, PLC CP1E, Float Switch Censor 


\section{Pendahuluan}

Air merupakan zat kehidupan, dimana tidak satupun mahluk hidup di planet bumi ini yang tidak membutuhkan air. Namun demikian perlu disadari bahwa keberadaan air di muka bumi ini sangat terbatas menurut ruang, dan waktu baik secara kuantitas maupun secara kualitas. Mengingat pentingnya peran air,sangat diperlukan adanya supplay air secara terus menerus. umumnya sumber air minum berasal dari air permukaan (surface water), air tanah (ground water) dan air hujan (Penggunaan air tanah salah satu alternatif yang dilakukan manusia guna memenuhi kebutuhan akan air baik untuk kebutuhan rumah tangga maupun kebutuhan industri. karena disamping mudah diperoleh juga sangat ekonomis.

\section{2 . TEORI DASAR}

Sensor Air yang digunakan adalah pelampung air otomatis (Float switch / Floating Control), pelampung dipasang pada Storage Tank sebagai indikator level air.

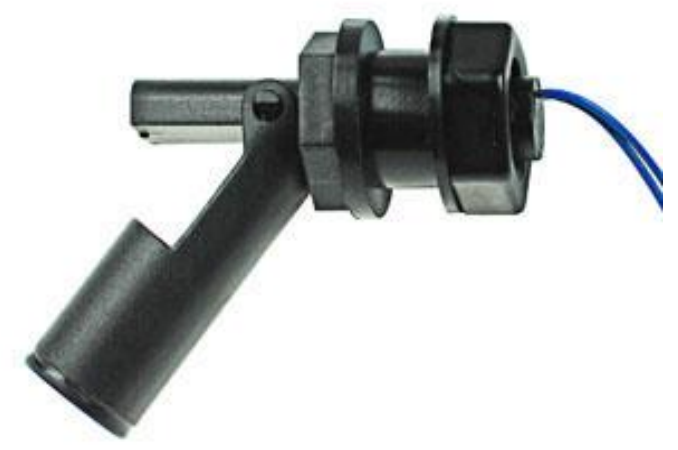

Gambar 1. Sensor Level Air

Prinsip Keria pelampung air otomatis (Float switch / Floating Control)

Pada posisi horizontal, apabila permukaan air turun, pelampung juga akan ikut turun, sehingga kontak akan berubah dari posisinya. Jika permukaan air naik lagi, maka pelampung akan naik dan kontak akan berubah lagi. Pada posisi vertikal, di dalam pelampung terdapat magnet tetap, yang bergerak naik turun yang mengikuti tinggi permukaan air. Di dalam pipa bagian tengah pelampung terdapat saklar yang membuka dan menutupnya dikerjakan oleh piston yang bergerak mengikuti magnet tetap di dalam pelampung.

\section{Pompa Air Aquarium}

Pompa air listrik ini penggunannya adalah dengan dicelupkan ke dalam air. Penggunaan umum pompa ini adalah untuk dipakai dalam aquarium untuk mengalirkan air ke tempat air sehingga air aquarium terjaga kebersihannya dalam jangka waktu yang lebih lama.

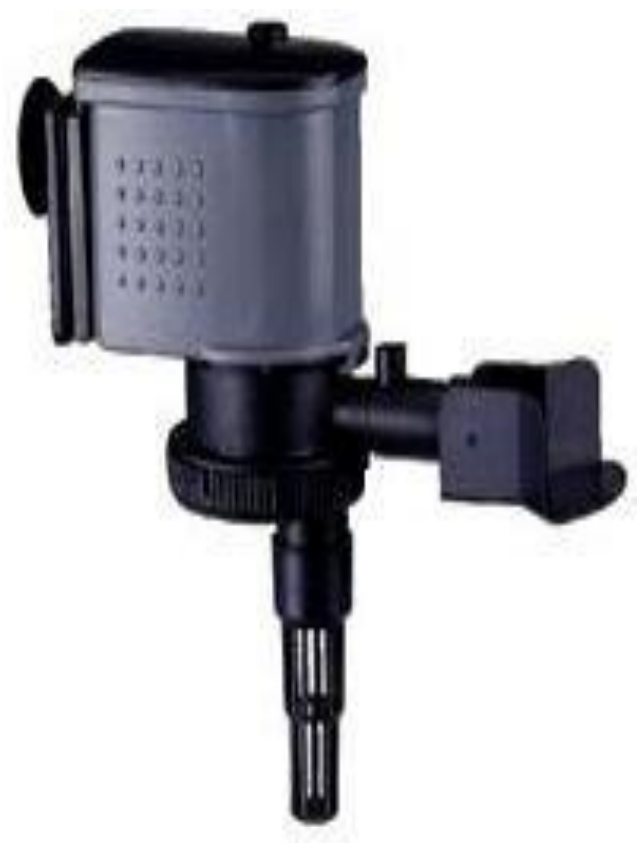

Gambar 2. Pompa aquarium

Prinsip kerja dari pompa ini adalah berdasarkan gaya sentrifugal yang dihasilkan oleh impeller yang diputar oleh motor listrik. Karena gaya ini air terdorong dari bawah ke atas melalui sirip sirip impeller.

\section{Selenoid valve}

Solenoid valve merupakan katup yang dikendalikan dengan arus listrik baik $A C$ maupun DC melalui kumparan / selenoida. Solenoid valve ini merupakan elemen kontrol yang paling sering digunakan dalam sistem fluida. Seperti pada sistem pneumatik, sistem hidrolik ataupun pada sistem kontrol mesin yang membutuhkan elemen kontrol otomatis. Contohnya pada sistem 
pneumatik, solenoid valve bertugas untuk mengontrol saluran udara yang bertekanan menuju aktuator pneumatic (cylinder). Atau pada sebuah tandon air yang membutuhkan solenoid valve sebagai pengatur pengisian air, sehingga tandon tersebut tidak sampai kosong.

\section{Prinsip kerja solenoid valve}

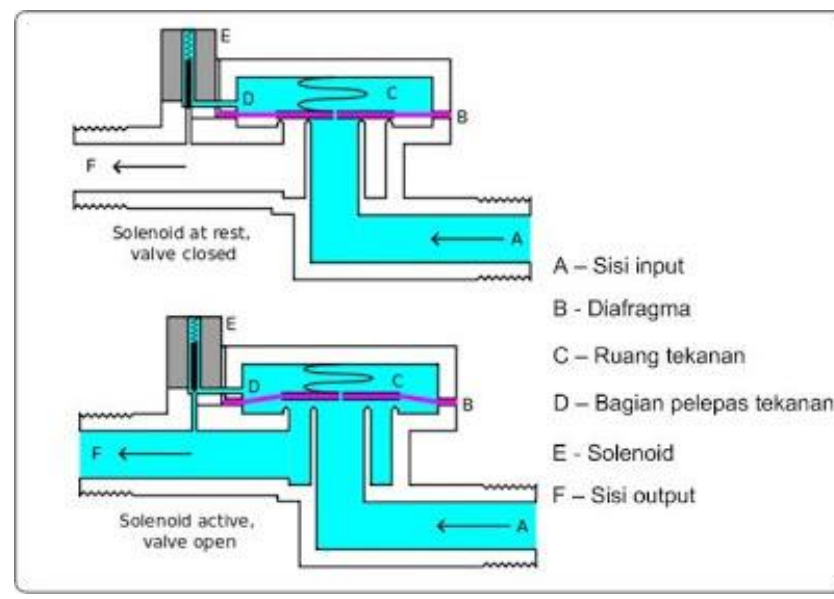

Gambar 3. Sistem kerja solenoid valve

Solenoid valve akan bekerja bila kumparan/coil mendapatkan tegangan arus listrik yang sesuai dengan tegangan kerja (kebanyakan tegangan kerja solenoid valve adalah 100/200VAC dan kebanyakan tegangan kerja pada tegangan DC adalah 12/24VDC). Dan sebuah pin akan tertarik karena gaya magnet yang dihasilkan dari kumparan selenoida tersebut. Dan saat pin tersebut ditarik naik maka fluida akan mengalir dari ruang $C$ menuju ke bagian $D$ dengan cepat. Sehingga tekanan di ruang $C$ turun dan tekanan fluida yang masuk mengangkat diafragma. Sehingga katup utama terbuka dan fluida mengalir langsung dari $A$ ke $F$. Untuk melihat penggunaan solenoid valve pada sistem pneumatik.

\section{Programmable Logic Controller (PLC)} Programmable Logic Control atau PLC dalam perancangan alat ini digunakan untuk mengatur nyala lampu monitoring pengisian air dari kosong sampai penuh dengan indikator menggunakan lampu LED 24 VDC.

\section{Keunggulan PLC dibanding Sistem Konvensional}

Salah satu keunggulan PLC dibanding sistem konvensional kontrol panel adalah sebagai berikut :

- Pada Progammable Logic Controller :

1. Pengawatan lebih sedikit.

2. Perawatan relatif mudah .

3. Pelacakan sistem lebih sedarhana.

4. Konsumsi daya relatif rendah.

5. Dokumentasi gambar lebih sederhana dan lebih mudah dimengerti.

6. Modifikasi sistem lebih sederhana dan cepat.

\section{Pada Sistem Konvensional Kontrol Panel:}

1. Pengawatan lebih kompleks.

2. Perawatan membutuhkan waktu yang lama.

3. Pelacakan kesalahan membutuhkan waktu yang lama.

4. Konsumsi daya yang relatif tinggi.

5. Dokumentasi gambar lebih banyak.

6. Modifikasi sistem membutuhkan waktu yang lama.

\section{PLC Omron CP1E}

Type PLC yang digunakan adalah PLC Omron CP1E-NA20DT-D.

Pada Supply tegangan yang dibutuhkan adalah 100-240 VAC 50/60 Hz dan power supply sebagai input tegangan ke PLC 24 VDC.

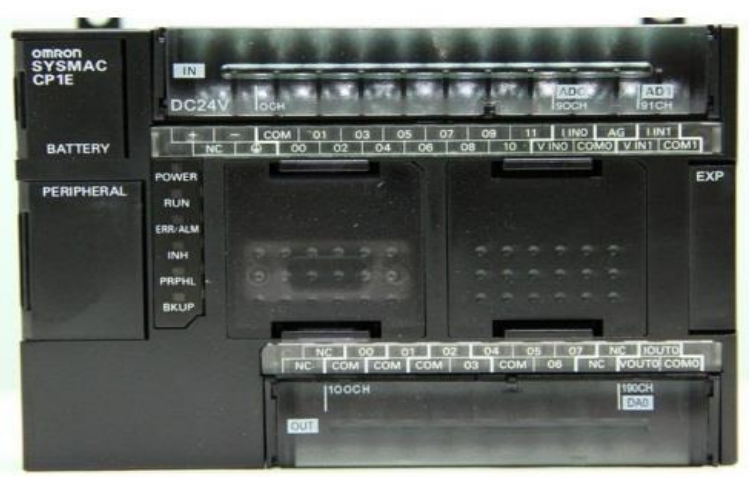

Gambar 4. PLC omron type CP1E 
Membuat Program dengan Software $C X$ Programmer

Pembuatan ladder diagram atau pemrograman yang menggunakan Komputer maka pembuatannya dengan software $C X-$ Programmer, software ini digunakan untuk membuat atau merancang ladder diagram dan untuk membuat intruksi - intruksi yang diinginkan oleh perancang untuk sebuah kontrol dan pengendalian. Tampilan software adalah sebagai berikut

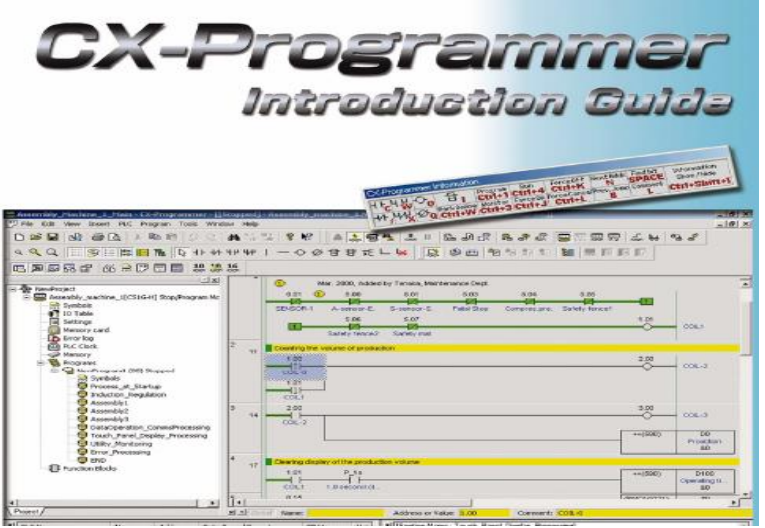

Gambar 5. Program CX-Programmer

\section{METODE PENELITIAN}

PERANCANGAN ALAT

\section{Tujuan Perancangan}

Perancangan alat perlu dilakukan untuk mengetahui apakah bisa diaplikasikan secara nyata di lapangan. Dalam proses perancangan, ditentukan komponenkomponen yang akan dipakai untuk memenuhi spesifikasi perangkat. Pemilihan komponen yang digunakan selain didasarkan atas kebutuhan sesuai spesifikasi juga perlu dilihat dari segi ketersediaannya dipasaran dan juga tentang harga komponen tersebut sehingga biaya pembuatan perangkat dapat ditekan dengan tidak meninggalkan kualitas perangkat yang dibuat.

\section{Tujuan Perancangan}

Perancangan alat perlu dilakukan untuk mengetahui apakah bisa diaplikasikan secara nyata di lapangan. Dalam proses perancangan, ditentukan komponenkomponen yang akan dipakai untuk memenuhi spesifikasi perangkat. Pemilihan komponen yang digunakan selain didasarkan atas kebutuhan sesuai spesifikasi juga perlu dilihat dari segi ketersediaannya dipasaran dan juga tentang harga komponen tersebut sehingga biaya pembuatan perangkat dapat ditekan dengan tidak meninggalkan kualitas perangkat yang dibuat.

Diagram blok alat selengkapnya dapat di lihat sebagai berikut:

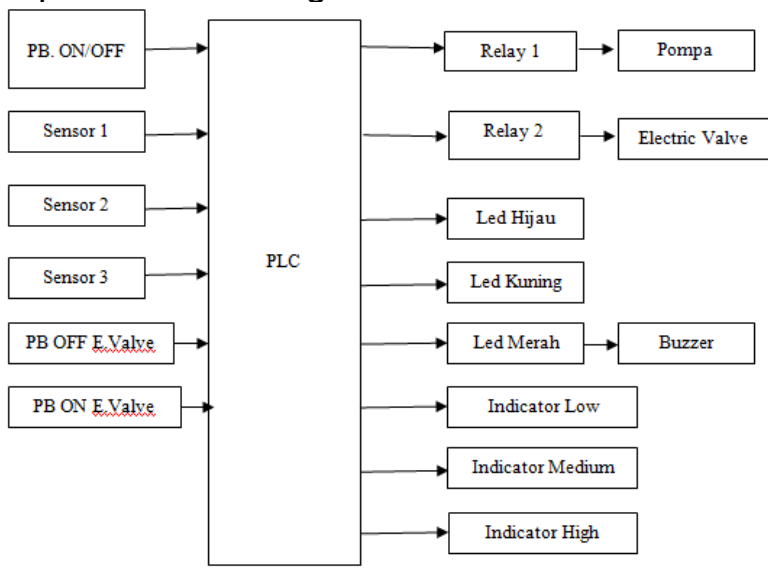

Gambar 6 Diagram blok kerja alat

\section{Cara Kerja :}

Awal tangki kosong sensor 1 pada posisi ON untuk memberi sinyal logic 1 pada input PLC, kemudian PLC akan mengaktifkan relay yang menjadikan pompa ON sehingga pengisian air ke dalam tangki berlangsung. Push button untuk mengatur buka tutup electric valve dan memastikan Electric valve dalam keadaan OFF saat pengisian air berlangsung.

Ketika tangki penuh, Sensor 3 menjadi ON untuk mengembalikan kontak relay menjadi posisi semula. Kontak NO menghentikan kerja pompa dan menghentikan perintah perhitungan pada PLC, Kontak level sudah NO menjadikan Electric valve pada posisi stand by dan siap untuk di ON untuk mengalirkan air dari tangki 2 ke tangki 1 .

\section{$\underline{\text { Tabel } 1 / 0}$}

Tabel pengalamatan input dan output PLC sesuai dengan perintah yang akan 
dijalankan, tabel input dan outputnya adalah sebagai berikut :

Tabel 1. I/O Pengalamatan PLC

\begin{tabular}{|c|c|c|c|}
\hline In & & Out & \\
\hline Keterangan & Addres & Keterangan & Addres \\
\hline P.B ON/OFF & 0.00 & $\begin{array}{c}\text { Relay 2 } \\
\text { Electric Valve }\end{array}$ & 10.000 \\
\hline Sensor 1 & 0.01 & Relay 1 Pompa & 10.001 \\
\hline Sensor 2 & 0.02 & Lampu Hijau & 10.002 \\
\hline Sensor 3 & 0.03 & Lampu Kuning & 10.003 \\
\hline $\begin{array}{c}\text { P.B OFF } \\
\text { Electric valve }\end{array}$ & 0.04 & $\begin{array}{c}\text { Lampu Merah \& } \\
\text { Buzzer }\end{array}$ & 10.004 \\
\hline P.B ON & 0.05 & Indicator Low & 10.005 \\
Electric valve & & & 10.006 \\
\hline & & Indicator Medium & 10.007 \\
\hline & & Indicator High & \\
\hline
\end{tabular}

\section{Diagram Time Chart}

Diagram time chart yang mendeskripsikan cara kerja keseluruhan proses Monitoring pengisian air ini sesuai pulsa yang dihasilkan oleh peralatan - peralatan inputnya dirancang sesuai gambar dibawah ini :
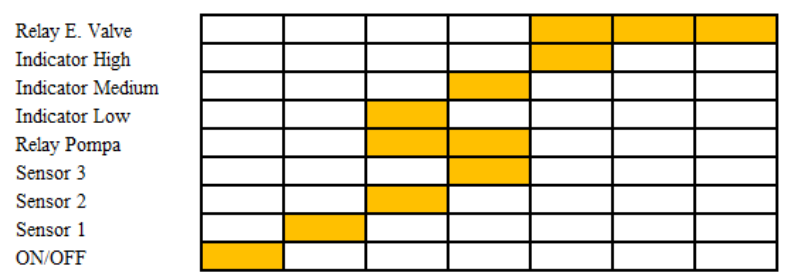

Lampu Hijau Lampu Kuning Lampu Hijau

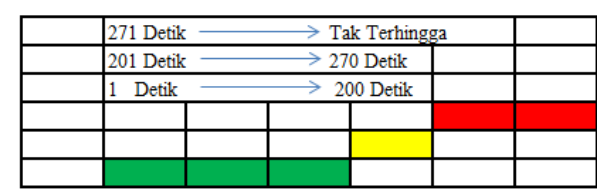

Gambar 7. Time chart kerja alat yang direncanakan.
Berikut penjelasan singkat prinsip kerja dari time chart monitoring pengisian air menggunakan PLC sebagai berikut:

Saat tombol Push button ON di tekan menandakan bahwa program siap untuk di operasikan, Dengan sensor 1 aktif akan mengaktifkan lampu indicator low dan menghidupkan pompa untuk memulai pengisian air ke dalam tangki, pada proses pengisian air berlangsung electric valve harus dalam keadaan off untuk mengetahui waktu pengisian dari low sampai high. Dengan sensor 2 aktif akan menghidupkan lampu indicator medium, menandakan pengisian air sudah mencapai setengah dari tangki. Dengan sensor 3 aktif akan mengaktifkan lampu indicator high menandakan proses pengisian air ke dalam tangki sudah terisi penuh, pada saat itu pula PLC mematikan kerja pompa dan electric valve dalam keadaan stand by siap untuk di ON untuk mengalirkan air dari tangki 2 ke tangki 1.

Pada saat sensor 1 ON sampai sensor 3 ON waktu lamanya pengisian 1 sampai 200 detik maka lampu indikator control hijau aktif, apabila waktu lamanya pengisian 201 sampai 270 detik maka lampu indikator kuning aktif, Dan apabila waktu lamanya pengisian 271 detik sampai tak terhingga maka lampu indicator control merah aktif bersamaan dengan bunyi buzzer menandakan bahwa terjadi trouble. 


\section{Wiring I/O}

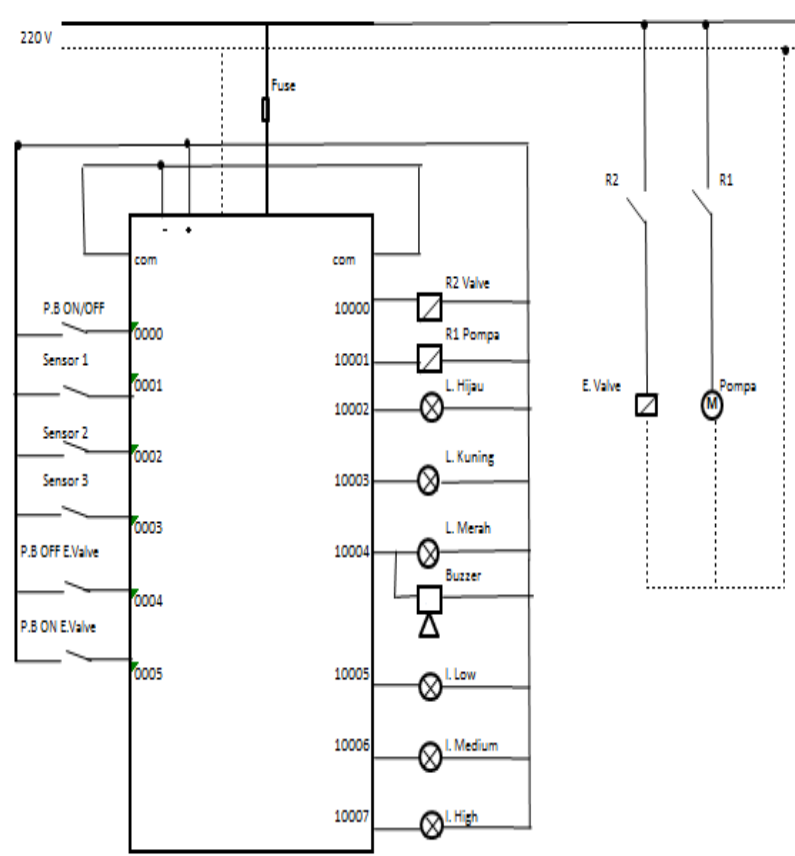

\section{Ladder diagram programing PLC}

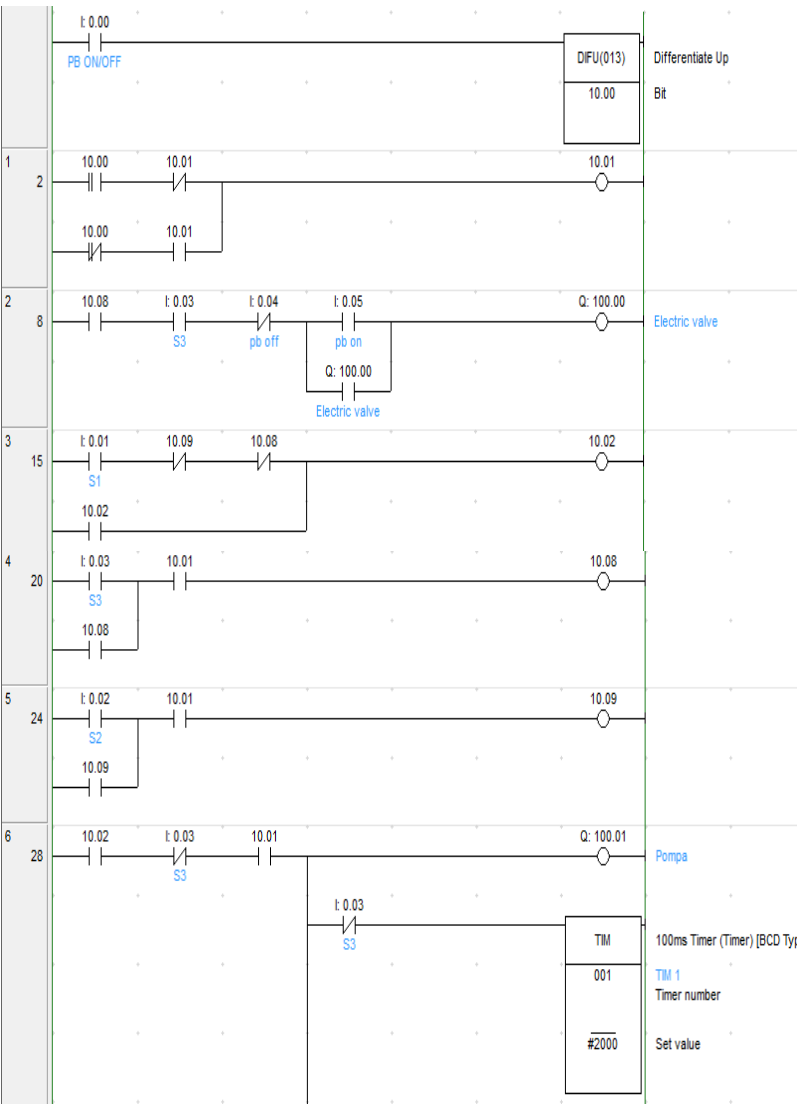

Saat tombol Push button ON di tekan menandakan bahwa program siap untuk di operasikan, awal tangki kosong sensor 1 aktif, dengan sensor 1 aktif maka pompa ON untuk memulai pengisian ke tangki, lamanya sensor 1 aktif hingga ke sensor 3 akan menyebabkan 3 kondisi yang berbeda .

1). Jika sensor 1 ke sensor 3 aktif 1-200 detik atau tangki terisi penuh di antara 1-180 detik maka lampu indikator hijau menyala dan mengidentifikasikan motor dalam keadaan baik (norma).

2). Jika sensor 1 ke sensor 3 aktif lebih dari 201 detik hingga 270 detik maka lampu indikator kuning menyala dan mengidentifikasikan pompa dalam dalam keadaan kurang baik (Warning).

Dalam hal ini pengguna di anjurkan untuk melakukan pengecekan kerena perfoma pompa mulai menurun.

3).Jika sensor 1 ke sensor 3 aktif lebih dari 271 detik sampai tak terhingga maka lampu indikator merah menyala sekaligus mengaktifkan buzzer dan mengidentifikasikan pompa dalam keaadan bermasalah (trouble). 
Dalam hal ini pengguna di anjurkan melakukan perbaikan karena pompa dalam keadaan bermasalah

Penguiian lama waktupengisiantangkidari sensor 1 (low) sampai sensor 3 (high) simulasikondisipompadalamkeadaan normal

Pengujian yang dilakukan adalah uji waktu pengisian tangki untuk simulasikan di isi pompa normal. Sesuai Limit switch yang dikendalikan oleh sensor 1 dan sensor 3 yaitu pompa menyala saat tangki kosong (Low) dan pompa mati saat tangki penuh (High).

Pengujian dilakukan untuk kalibrasi waktu pengisian tangki yang akan disesuaikan dengan program PLC sebagai batasan maksimal waktu yang diperbolehkan untuk pengisian tangki.

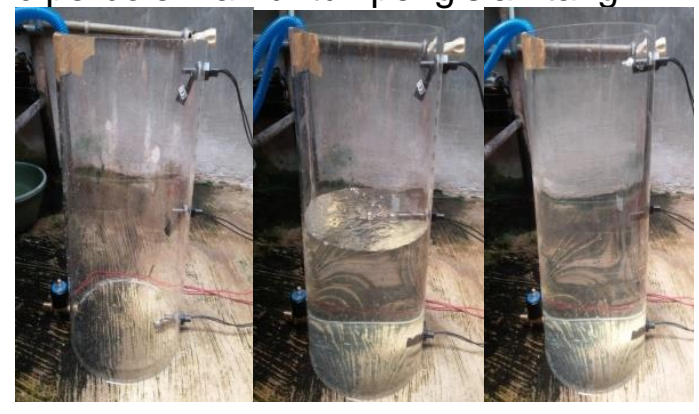

(1)

(2)

(3)

Gambar 9. Storage TankLow, Medium, dan High.

Pengujian waktu pengisian tangki pompa normal.

\begin{tabular}{|l|c|c|c|}
\hline Percobaan & $\begin{array}{c}\text { Setting } \\
\text { waktu } \\
\text { (detik) }\end{array}$ & $\begin{array}{c}\text { Aktual } \\
\text { Waktu } \\
\text { (detik) }\end{array}$ & Kondisi \\
\hline \hline Percobaan 1 & 200 & 193 & OK \\
\hline Percobaan 2 & 200 & 190 & OK \\
\hline Percobaan 3 & 200 & 195 & OK \\
\hline Percobaan 4 & 200 & 196 & OK \\
\hline Percobaan 5 & 200 & 198 & OK \\
\hline
\end{tabular}

Pada Tabel di atas Jika waktu pengisian dari sensor 1 (Low) sampai sensor 3 (High) tangki terisi penuh di antara 1-200 detik,maka lampu indicator control hijau menyala dan mengidentifikasikan motor dalam keadaan baik (Normal).

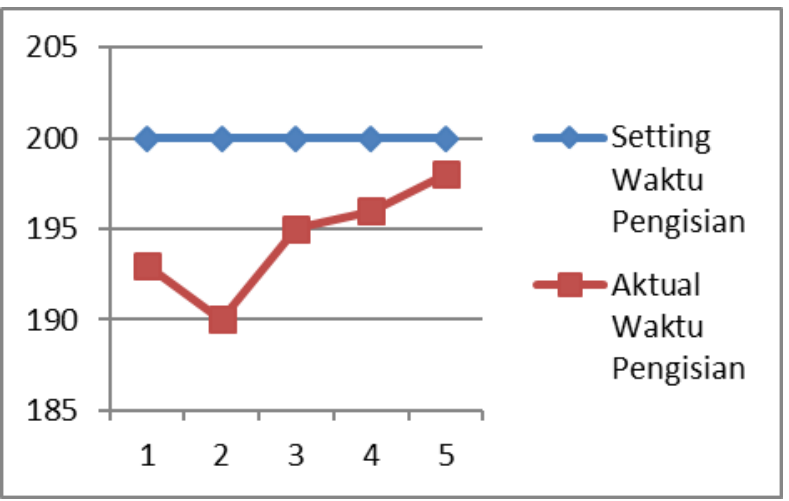

Gambar 10. Grafik Pengujian waktu pengisian tangki pompa normal

Hasil grafik menunjukkan dari 5 percobaan dengan setting waktu pengisian air kedalam tangki 200 detik.Pada percobaan 1 sampai ke 5 menunjukkan hasil actual pengisian 193, 190, 195, 196,dan 198 detik. Dimana 5 percobaan tersebut berada di bawah waktu pengisian 200 detik sehingga pengisian di katakan normal.

\section{Pengujian lama waktu pengisian tangki dari sensor 1 (low) sampai sensor 3 (high) dalam keadaan warning.}

Pengujian dilakukan jika pompa mulai melemah dengan simulasi memutar sedikit Valve manual yang ada di pompa untuk memperoleh waktu pengisian tangki yang agak lama. 
Tabel Penqujian waktu pengisian tangki pompa mulai melemah

\begin{tabular}{|l|c|c|c|}
\hline \hline Percobaan & $\begin{array}{c}\text { Setting } \\
\text { waktu } \\
\text { (detik) }\end{array}$ & $\begin{array}{c}\text { Aktual } \\
\text { Waktu } \\
\text { (detik) }\end{array}$ & Kondisi \\
\hline \hline Percobaan 1 & 270 & 265 & Warning \\
\hline Percobaan 2 & 270 & 267 & Warning \\
\hline Percobaan 3 & 270 & 268 & Warning \\
\hline Percobaan 4 & 270 & 266 & Warning \\
\hline Percobaan 5 & 270 & 264 & Warning \\
\hline
\end{tabular}

Pada Tabel di atas jika waktu pengisian dari sensor 1 (Low) sampai sensor 3 (High) tangki terisi penuh di antara 201270 detik maka lampu indicator control kuning menyala dan mengidentifikasikan motor dalam keadaan kurang baik (warning).

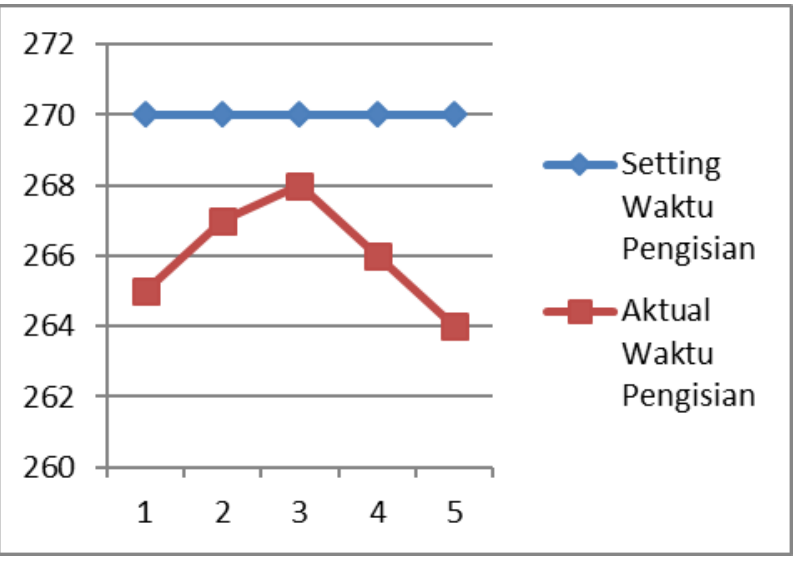

Gambar 11. Grafik Pengujian waktu pengisian tangki pompa mulai melemah.

Hasil grafik menunjukkan dari 5 percobaan dengan setting waktu pengisian air kedalam tangki 270 detik. Pada percobaan 1 sampai ke 5 menunjukkan hasil actual pengisian $265,267,268,266$, dan 264 detik. Dimana 5 percobaan tersebut berada di atas waktu pengisian normal 200 detik sehingga pengisian di katakan warning.
Penquiian lama waktu pengisian tangki dari sensor 1 (low) sampai sensor 3 (high) dalam keadaan trouble.

Pada pengujian kali ini dilakukan simulasi saat pompa dalam keadaan bermasalah dengan cara menutup Valve manual yang ada pada pompa sehingga aliran air ke tangki sudah tidak ada dan tangki tidak terisi.

Tabel Pengujian waktu pengisian tangki pompa bermasalah.

\begin{tabular}{|l|l|l|l|}
\hline Percobaan & $\begin{array}{l}\text { Setting } \\
\text { waktu } \\
\text { (detik) }\end{array}$ & $\begin{array}{l}\text { Aktual } \\
\text { Waktu } \\
\text { (detik) }\end{array}$ & Kondisi \\
\hline \hline Percobaan 1 & 270 & $\sim$ & Alarm \\
\hline Percobaan 2 & 270 & $\sim$ & Alarm \\
\hline Percobaan 3 & 270 & $\sim$ & Alarm \\
\hline Percobaan 4 & 270 & $\sim$ & Alarm \\
\hline Percobaan 5 & 270 & $\sim$ & Alarm \\
\hline
\end{tabular}

PadaTabel Jika waktu pengisian dari sensor 1 (Low) sampai sensor 3 (High) tangki terisi penuh di antara 171 detik sampai tak terhingga maka lampu indicator control merah menyala sekaligus mengaktifkan buzzer dan mengidentifikasikan motor dalam keadaan bermasalah (trouble). Dalam hal ini pengguna di anjurkan untuk melakukan perbaikan karena pompa dalam keadaan bermasalah.

Di tunjukkan bahwa Alarm trouble akan menyala saat waktu maksimal yang ada diprogram tercapai. Kondisi ini menunjukkan bahwa simulasi monitoring pewaktuan pengisian air dari sumber sampai ketangki sudah bekerja. 


\section{KESIMPULAN}

Dengan hasil Monitoring dengan alat yang di buat dapat disimpulkan bahwa :

1. Alat monitoring menggunakan PLC menginformasikan pengisian normal di bawah waktu 200 detik dengan menyalanya lampu indicator hijau dan akan menginformasikan pengisian tidak normal saat waktu pengisian melebihi 270 detik dengan menyalanya lampu indicator merah, untuk setiap pengisian tangki bervolume 21 liter.

2. Program Monitoring waktu pengisian air ke tangki menggunakan software CX-Programmer, dimana waktu pengisian normal $<200$ detik dan waktu pengisian tidak normal $>270$ detik.

\section{DAFTAR PUSTAKA}

1. Zamidra Zam, Efvy. 2005. Panduan Praktis Belajar Elektronika. Surabaya: Indah.

2. Suratman. 2001. Kamus Elektronika. Bandung: CV, Pustaka Grafika.

3. Soleh Miftahu, Teknik Kontrol, Kementrian Pendidikan dan Kebudayaan Republik Indonesia, 2013.

4. Iwan Setiawan, 2006, Programable Logic Controller (PLC) dan Teknik Perancangan Sistem Kontrol, Penerbit ANDI, Yogyakarta

5. Omron. (1993). CPM2A Program mable Controllers Operation Manual Omron. (2001).

6. CPM1/CPM1A/CPM2A/CPM2C/SRM 1(-V2) Programmable Controllers Programming Manual.

7. Jatmiko, S.S. 2003. Desain dan Pembuatan Catu Daya Plasma DC Tegangan Tinggi untuk Reaktor DCUBM Sputtering. Skripsi. Semarang: FMIPA Universitas Negeri Semarang.

8. Sugeng, Bahan ajar PLC Balai Latihan Kerja Industri, Provinsi Banten.
9. Modul Pratikum Elektromekanik, Balai Latihan Kerja Industri, Provinsi Banten. 